\title{
A Repetitive Acceptance Sampling Plan for Generalized Inverted Exponential Distribution Based on Truncated Life Test
}

\author{
Navyodh Singh ${ }^{1}$, Navjeet Singh ${ }^{2 *}$, Harpreet kaur ${ }^{3}$ \\ ${ }^{1}$ Department of Mathematics, Sant Baba Bhag Singh University, Jalandhar, India \\ ${ }^{2}$ Department of Mathematics, Sant Baba Bhag Singh University, Jalandhar, India \\ ${ }^{3}$ Department of Mathematics, Sant Baba Bhag Singh University, Jalandhar, India \\ *Corresponding Author: navjeet8386@yahoo.com
}

Available online at: www.isroset.org

Received: 17/May/2018, Revised: 28/May/2018, Accepted: 16/Jun/2018, Online: 30/Jun/2018

\begin{abstract}
In this paper, we consider the generalized inverted exponential distribution (GIED) as a life model to develop various acceptance sampling schemes for truncated life tests. We develop the repetitive acceptance sampling plan (RASP) by attributes based on truncated life test and determine the design parameters satisfying both the producer's risk $(\alpha)$ and consumer's risk $(\beta)$ simultaneously for the specified quality levels in terms of true median life ratio to the specified life. We are also to minimize average sample number where the constraints are related to the lot acceptance probabilities at the acceptance and limiting quality levels. The performance of the proposed plan is compared with single acceptance sampling plan under the GIED. The proposed sampling plan reduces the average sample number as compare to the single acceptance sampling plan. Tables are obtained for various values of shape parameter and the results are discussed. Also, discussion about the effect of misspecification of shape parameter is explained.
\end{abstract}

Keywords - Consumer's risk, repetitive acceptance sampling plan, median life, generalized inverted exponential distribution, producer's risk.

\section{INTRODUCTION}

In global business market reputation of each business, group depends upon the quality and reliability of their products. The improvement in quality and reliability of products lead to achieve success in business and give an upper edge in this competitive world. In the various statistical analysis, acceptance sampling plans are a channel to acquire adequate inferential information about the quality and reliability of the products. Acceptance sampling plans provide a direction for consumers to make a conjecture about the reliability and quality of a product lot from a sample. An entire lot of products, either accepted or rejected, depends upon whether some or a large number of bad items is found in the sample. Thus, a sampling plan provides the idea about the acceptance or non-acceptance of the items from the given lot. These sampling plans provide appropriate knowledge to producers to improve the quality level of products as well as to awaken the consumers not to accept the bad products. Usually, acceptance sampling plan gives assistance to acquire an ideal sample size of items at given consumer's and the producer's risks. Various sampling plans are available from the past which deals to test the quality of products and they include single sampling plan and group acceptance sampling plans.
Due to simplicity in practice, single acceptance sampling plan is commonly applied.

In single acceptance sampling plan, a truncated life test examination in which $n$ items are randomly selected from a lot of products and placed on a life testing experiment for pre-assigned time units to. We are to examine the lot for to units of time and if the number of failed units is larger than the established acceptance $c$ then reject the lot. Otherwise, the lot is accepted if the total number of observed failures are $c$ or fewer before time to. Here $n$ and $c$ are design parameters of the single acceptance sampling plan. For to greater extent about the single acceptance sampling plan, it is advised to see [1], [2] and [3].

In this paper, we develop a new repetitive acceptance sampling plan (RASP) based on the median lifetime of products for a generalized inverted exponential distribution (GIED). [4] proposed the attribute repetitive group acceptance sampling plan for a normal distribution. According to [4], the developed repetitive group acceptance sampling plan gives an optimal sample size corresponding to the consumer's risk. Furthermore, repetitive acceptance sampling plan is more efficient than ordinary sampling plan. 
Several authors, [5] introduced a variable repetitive acceptance sampling plan and compared their results with single acceptance sampling scheme for normal distribution. The rest of the paper is organized as follows: - Section I contains the introduction of acceptance sampling plan based on truncated life test. Section II contains the useful information about the properties of GIED. Section III contains the detail explanation of repetitive acceptance sampling plan (RASP) and table 1, 2, 3 are discussed. Section IV contains the result and discussion about the comparative analyses between proposed RASP and single acceptance sampling plan and an example is given. Section V contains the discussion about misspecification of shape parameter. Section VI concludes research work.

\section{GENERALIZED INVERTED EXPONENTIAL DISTRIBUTION (GIED)}

Two parameters generalized inverted exponential distribution (GIED) was discussed in the literature by [6]. Also, some useful properties of inverted exponential distribution described in [7] and [8]. The probability density function (PDF) and cumulative distribution function (CDF) of the form

$f(t ; \lambda, \gamma)=\lambda \gamma t^{-2} e^{\frac{-\lambda}{t}}\left(1-e^{\frac{-\lambda}{t}}\right)^{\gamma-1} ; t>0, \lambda>0, \gamma>0$,

$F(t ; \lambda, \gamma)=1-\left(1-e^{\frac{-\lambda}{t}}\right)^{\gamma}$.

(1)

where $\gamma$ is a shape parameter and $\lambda$ is scale parameter of the distribution. Further, it has been recommended that this distribution gives a better fit than other models like Gamma, Generalized exponential, Weibull, and Inverted exponential distribution. For further details, see [9], [10] and [11]. The mean $\mu$ of $\operatorname{GIE}(\gamma, \lambda)$ distribution is given by:

$\mu=\lambda \int_{0}^{\infty} x^{-2}\left(1-e^{-x}\right)^{\gamma} d x$,

which exists for $\gamma>1$. The corresponding 100pth percentile $\theta_{p}=F^{-1}(\mathrm{p})$ points is given by:

$\theta_{p}=-\frac{\lambda}{\log \left(1-(1-p)^{\frac{1}{\gamma}}\right)}$

and is defined for all parameters. Note that the median life of GIE distribution is given by:

$m_{d}=-\frac{\lambda}{\log \left(1-0.5^{\frac{1}{\lambda}}\right)}$

\section{REPETITIVE ACCEPTANCE SAMPLING PLAN (RASP)}

Since the plan is drafted to be used in which life time of product follows GIE distribution. A manufacturer submits a lot of units and claims that the $\mathrm{m}_{\mathrm{o}}$ is specified median life of the units. The actual median lifetime $\left(\mathrm{m}_{\mathrm{d}}\right)$ will be used as the quality parameter for the test units. We are interested to formulate the null hypothesis and alternative hypothesis, $\mathrm{H}_{0}$ : $\mathrm{m}_{\mathrm{d}} \geq \mathrm{mo}_{\mathrm{o}}$ and $\mathrm{H}_{1}: \mathrm{m}_{\mathrm{d}}<\mathrm{mo}_{\mathrm{o}}$ respectively. The null hypothesis (Ho) is accepted means the submitted lot of units considered to be a good and alternative hypothesis $\left(\mathrm{H}_{1}\right)$ is accepted means the submitted lot of units considered to be bad based on the information obtained from the lot selected from an infinite lot for $t_{o}$ units of time in a life test experiment. For convenience, write the experiment time to as some multiple of specified median lifetime $\mathrm{m}_{\mathrm{o}}$. i.e. $\mathrm{t}_{\mathrm{o}}=\mathrm{am}_{\mathrm{o}}$, for any positive constant a. By using the following sampling plan, the hypothesis can be tested:-

(1) Draw a random sample of size $n$ units and put them on a life test for prefixed $t_{0}$ units of time.

(2) Accept $H_{0}: m_{d} \geq m_{o}$ if the number of failed units (d) is smaller than or equal to $c_{1}$ (first acceptance number) and declare that the product lot is good. Stop or truncate the test if $\mathrm{H}_{1}: \mathrm{m}_{\mathrm{d}}<\mathrm{m}_{\mathrm{o}}$ and reject the product lot as soon as the number of defective exceeds $c_{2}$, where $c_{1} \leq c_{2}$.

(3) If $c_{1}<d \leq c_{2}$, then go to step (1) and repeat the experiment.

In the above-stated plan, $n, c_{1}, c_{2}$ are three parameters. If $\mathrm{c}_{1}=\mathrm{c}_{2}=\mathrm{c}$, the above-mentioned plan is reduced to a single acceptance sampling plan. Now the probability for RASP at the first sample is given by:-

$P_{a}(p)=P\left(d \leq c_{1} \mid p\right)=\sum_{k=0}^{c_{1}}\left(\left(\begin{array}{l}n \\ k\end{array}\right) p^{k}(1-p)^{n-k}\right)$

and the probability of rejection at the first sample is given by:-

$P_{r}(p)=P\left(d>c_{2} \mid p\right)=1-\sum_{k=0}^{c_{2}}\left(\left(\begin{array}{l}n \\ k\end{array}\right) p^{k}(1-p)^{n-k}\right)$.

Hence, the lot acceptance sampling based on RASP is:-

$P_{A}(p)=\frac{P_{a}(p)}{P_{a}(p)+P_{r}(p)} ; 0<\mathrm{p}<1$.

Here $\mathrm{p}$ is the probability of test units fails before the termination time $t_{0}$ for GIE distribution using (4) and $t_{0}=a_{0}$ is given by:-

$p=1-\left[1-\left(1-0.5^{1 / \gamma}\right)^{\frac{m_{d}}{a m_{o}}}\right]^{\gamma}$ 
Notice that $\mathrm{p}$ is dependent upon the median lifetime ratio $\frac{m_{d}}{m_{o}}$ and independent of the scale parameter $\lambda$. The RASP's parameters $n, c_{1}$ and $c_{2}$ can be determined by solving the following two inequalities simultaneously:-

$P_{a}\left(p_{1} \mid \frac{m_{d}}{m_{o}}=r_{1}\right) \leq \beta$

$P_{a}\left(p_{2} \mid \frac{m_{d}}{m_{o}}=r_{2}\right) \geq 1-\alpha$

where $\mathrm{p}_{1}$ is the probability of failure units before termination time $t_{0}$ corresponding to consumer's risk $(\beta)$ when the quality level is $r_{1}$ and $p_{2}$ is the probability of failure units before termination time $t_{0}$ corresponding to producer's risk $(\alpha)$ when the quality level is $r_{2}$. There may exist multiple solutions of design parameters satisfying the above two inequalities (9) and (10). Therefore, we would favor those values of design parameters which are to minimize the average sample number (ASN). The ASN for the proposed RASP is stated as follows:-

$$
\operatorname{ASN}(p)=\frac{n}{P_{a}(p)+P_{r}(p)}
$$

Therefore, the design parameters for our RASP having minimum sample size will be obtained by solving the following optimization problem:-

$\operatorname{Minimize} \operatorname{ASN}(p)=\frac{n}{P_{a}(p)+P_{r}(p)}$

Subject to

$P_{a}\left(p_{1}\right) \leq \beta$,

$P_{a}\left(p_{2}\right) \geq 1-\alpha$,

where $\mathrm{n}$ is an integer.

Here we consider three values of the shape parameter $(\gamma=$ 1, 2, 3) for the RASP of GIE distribution. We are to determine the design parameters of proposed RASP when $a=0.5,1.0$, four levels of the consumer's risk $(\beta)$ taken as $0.25,0.10,0.05,0.01$ and producer's risk $(\alpha)$ taken as 0.05 for quality levels $\left(\mathrm{r}_{2}=1.5,2.0,2.5,3.0,3.5,4.0\right)$ which are satisfying the above optimization problem are explained by table 1,2 and 3.

The lot acceptance probability $\left(p_{\alpha}\right)$ corresponding to producer's risk $(\alpha)$ and ASN with quality level $r_{2}$ are also mentioned in each table. In these tables, note that as the quality level $\mathrm{r}_{2}$ increases the design parameters and ASN decreases whereas the probability of acceptance increases. As the time termination ratio increases from $a=0.5$ to $a=1.0$ and $r_{2} \geq 2$ the design parameter $n$ tends to decrease. For example, for $\gamma=1, \mathrm{a}=0.5, \mathrm{r}_{2}=2.5, n=12$ and for $\mathrm{a}=1.0, \mathrm{r}_{2}=$
2.5, $n=8$. Same pattern is observed in table 2 and 3 , whereas ASN is less for $\mathrm{a}=1.0$ than $\mathrm{a}=0.5$ at all the quality levels $\left(\mathrm{r}_{2}=1.5,2.0,2.5,3.0,3.5,4.0\right)$ and shape parameter $\gamma$ $=2,3$.

\section{RESULT AND DISCUSSION}

In table 4, we are comparing the repetitive acceptance sampling plan (RASP) with single acceptance sampling plan (SASP) in terms of sample size required. Money and time are saved if we have small size samples. It is observed that RASP requires smaller sample size than the SASP excluding those cases where acceptance number $c=0$. Acceptance number is written in parenthesis for the single sampling plan. Similar trends are observed for different shape parameter and test time termination multiplier. This difference decreases when the quality level $r_{2}$ increases.

Example: Suppose that life time of a product follows the $\operatorname{GIED}(2, \lambda)$ and experimenter is interested in adopting the RASP to make a decision about the submitted lots that they will be accepted or rejected. The submitted lot of units by the producer claims that the specified life time of a unit is 1000 hours. He puts all the units for the experiment up to 1000 hours. It is known that the consumer's risk is $10 \%$, when the true median life is 1000 hours, whereas the producer's risk is $5 \%$, when the true median life is 2000 hours. In this case, we have, $\mathrm{a}=1.0, \gamma=2, \mathrm{~m}_{\mathrm{o}}=1000$ hours, $\beta=0.10, \alpha=0.05$, the quality level at consumer risk is 1 and at producer risk is 2 , so from table 2 , we get the design parameters $\left(n, \mathrm{c}_{1}, \mathrm{c}_{2}\right)=(8$, $1,3)$ and $\mathrm{AS} \mathrm{N}=11.91$. The producer draws a random sample of 8 units and put them on a life test for 1000 hours and the lot will be rejected if more than 3 units are found to defective. If the number of failures is less than 1 then the lot is accepted and if the number of failures is between 1 and 3 then the experiment is repeated.

\section{EFFECT OF MISSPECIFICATION OF THE SHAPE PARAMETER}

In this section, we would investigate the effect of misspecification of shape parameter on the lot acceptance probabilities for producer's risk $(\alpha)$ and consumer's risk $(\beta)$. Some writers have earlier done work on the misspecification of shape parameter on various sampling plans like [9], [12] and [13] has used GIED for multiple deferred state sampling plan. Suppose that true shape parameter $\left(\gamma_{o}\right)$ and the specified shape parameter $(\gamma)$ for the designed sampling plan which is different from the true shape parameter $\gamma_{o}$.

Let $p_{1}^{o}$ and $p_{2}^{o}$ be the probabilities of failure corresponding to producer's risk and consumer's risk respectively for the true shape parameter. Then 
$p_{1}^{o}=1-\left[1-\left(1-0.5^{1 / \gamma_{o}}\right)^{\frac{m_{d}}{a m_{o}}}\right]^{\gamma_{o}}$

$p_{2}^{o}=1-\left[1-\left(1-0.5^{1 / \gamma_{o}}\right)^{\frac{m_{d}}{a m_{o}}}\right]^{\gamma_{o}}$

Therefore, the probabilities of acceptance at producer's risk $(\alpha)$ and different levels of consumer's risk $(\beta)$ will be $P_{a}\left(p_{1}^{o}\right)$ and $P_{a}\left(p_{2}^{o}\right)$ respectively derived from equation (9) and (10), where the parameters $\left(n, c_{1}, c_{2}\right)$ are calculated for the specified shape parameter $\gamma$. If there is no problem from the misspecification of shape parameter as they still satisfy the two inequalities

$P_{a}\left(p_{1}^{o}\right) \leq \beta$

$P_{a}\left(p_{2}^{o}\right) \geq 1-\alpha$

then this value of shape parameter is also good. Table 5 reports the lot acceptance probabilities at producer's risk $(\alpha)$ for the RASP with the time termination multiplier $a=0.5$ when the true shape parameter takes values given by $\gamma_{o}=4.3$, $4.8,5.3,5.8,6.3$ and quality levels $r_{2}=1.5,2.0,2.5,3.0$. Next, we observed that when the true shape parameter is more than the specified shape parameter the probabilities at consumer's risk $(\beta)$ are not satisfied. From table 6 , we notice that when $a=1.0$ the mis-specification of true shape parameters has no effect on the lot acceptance probabilities and both the above equations (14) and (15) are satisfied.

\section{Conclusion}

In this article, we proposed an attribute repetitive acceptance sampling plan based on truncated life test when the life time of the submitted lot follows a generalized inverted exponential distribution. The design parameters were calculated by considering the median life time of the product which satisfies both producer's risk and consumer's risk simultaneously for different shape parameters. The proposed plan is compared with the ordinary single acceptance sampling plan and we observed from the comparison that the proposed plan is more economical than existing one as it provides smaller sample size than the ordinary single acceptance sampling plan. We examined the effect of misspecification of the shape parameter on the lot acceptance probabilities at producer's risk and consumer's risk. So, the proposed plan is highly advised for testing mechanical equipment and electronic devices, when the generalized inverted exponential distribution is followed by them. The approach can be extended to other probabilistic distributions.

\section{ACKNOWLEDGMENT}

The author would like to acknowledgment the thanks to the referees for their valuable suggestion and comments to improve the quality of the paper.

\section{REFERENCES}

[1] B. Epstein, "Truncated life tests in the exponential case", The Annals of Mathematical Statistics, 25(3),pp.555-564, 1954.

[2] N. Balakrishnan, 1. Leiva, and J. Lopez, "Acceptance sampling plans from truncated life tests based on the generalized BirnbaumSaunders distribution", Communications in Statistics-Simulation and Computation. 36, pp.643-656, 2007.

[3] T.R. Tsai and S.J. Wu., "Acceptance sampling based on truncated life tests for generalized Rayleigh distribution", Journal of Applied Statistics, 33(6), pp.595-600, 2006.

[4] R.E. Sherman, "Design and evaluation of repetitive group sampling plan", Technometrics, 7:1121, 1965.

[5] S. Balamurali, C.H. Jun, "Repetitive group sampling procedure for variables inspection", Journal of Applied Statistics, 33(3):327338, 2006.

[6] A. M. Abouammoh, and A. M. Alshingiti, "Reliability estimation of generalized inverted exponential distribution", Journal of Statistical Computation and Simulation, 79, pp.1301-1315, 2009.

[7] A.Z. Killer and A.R.R. Kamath, "Alternative reliability models for mechanical systems" third international conference on reliability and maintainability,18-21 October, Tousle, France, 1982.

[8] S. Dey,"Inverted exponential distribution as a life distribution model from a Bayesian viewpoint", Data Science Journal, 6, pp.107-113, 2007.

[9] Sukhdev Singh and Yogesh Mani Tripathi and Chi-Hyuck Jun,"Sampling plans based on truncated life test for a generalized inverted exponential distribution", Industrial Engineering Management Systems, 14(2), pp.183-195, 2015.

[10] H. Krishna and K. Kumar,"Reliability estimation in generalized inverted exponential distribution with progressively type II censored sample", Journal of Statistical Computation and Simulation, 83, pp.1007-1019, 2013.

[11] S. dey and B. Pradhan, "Generalized inverted exponential distribution under hybrid censoring", Statistical Methodology. http://dx.doi.org/10.1016/j.stamet.2013.07.007.

[12] M. Aslam, M. Azam,, and C.H. Jun, "Decision rule based on group sampling plan under the inverse Gaussian distribution", Sequential Analysis,32, pp.71-82, 2013.

[13] S. Balamurali, P. Jeyadurga, and M. Usha, "Designing of multiple deferred state sampling plan for generalized inverted exponential distribution", Sequential Analysis,36(1), pp.76-862017.

\section{AUTHORS PROFILE}

Navyodh Singh is Research Scholar is now pursuing his Ph.D. in Mathematics in Department of Mathematics of Sant Baba Bhag Singh University. His field of research is Acceptance Sampling Theory.

Navjeet Singh is Research Scholar is now pursuing his Ph.D. in Mathematics in Department of Mathematics of Sant Baba Bhag Singh University. His field of research is Acceptance Sampling Theory.

Harpreet Kaur is working as Head of Department of Mathematics of Sant Baba Bhag Singh University. She has 20 years teaching experience at P.G. level. She has published 33 research papers in which 10 papers are in international journals. 
Table 1: Minimum average sample number(ASN) and acceptance numbers when $\gamma=1$

\begin{tabular}{|c|c|c|c|c|c|c|c|c|c|c|c|}
\hline \multirow{2}{*}{$\beta$} & \multirow{2}{*}{$r_{2}$} & \multicolumn{5}{|c|}{$a=0.5$} & \multicolumn{5}{|c|}{$\mathrm{a}=1.0$} \\
\hline & & $\mathrm{C}_{1}$ & $\mathrm{C}_{2}$ & $\mathrm{n}$ & $\mathrm{p}_{\alpha}$ & ASN & $\mathrm{C}_{1}$ & $\mathrm{C}_{2}$ & $\mathrm{n}$ & $\mathrm{p}_{\alpha}$ & ASN \\
\hline \multirow[t]{6}{*}{0.25} & 1.5 & 5 & 7 & 32 & 0.9527 & 44.41 & 14 & 17 & 35 & 0.9543 & 53.41 \\
\hline & 2.0 & 1 & 2 & 12 & 0.9594 & 15.63 & 3 & 5 & 11 & 0.9541 & 17.93 \\
\hline & 2.5 & 1 & 1 & 12 & 0.9628 & 10.0 & 2 & 3 & 8 & 0.9577 & 10.24 \\
\hline & 3.0 & 1 & 1 & 10 & 0.9899 & 10.0 & 2 & 2 & 7 & 0.9536 & 7.0 \\
\hline & 3.5 & 0 & 0 & 5 & 0.9615 & 5.0 & 0 & 1 & 3 & 0.9717 & 4.8 \\
\hline & 4.0 & 0 & 0 & 5 & 0.9806 & 5.0 & 0 & 1 & 3 & 0.9865 & 4.8 \\
\hline \multirow[t]{6}{*}{0.10} & 1.5 & 3 & 7 & 29 & 0.9568 & 59.33 & 14 & 19 & 39 & 0.9526 & 70.38 \\
\hline & 2.0 & 2 & 3 & 21 & 0.9568 & 23.78 & 5 & 7 & 17 & 0.9500 & 22.45 \\
\hline & 2.5 & 0 & 1 & 9 & 0.9611 & 11.61 & 2 & 4 & 11 & 0.9572 & 14.50 \\
\hline & 3.0 & 0 & 1 & 9 & 0.9907 & 11.61 & 0 & 2 & 5 & 0.9696 & 9.41 \\
\hline & 3.5 & 0 & 1 & 9 & 0.9977 & 11.61 & 1 & 2 & 7 & 0.9795 & 8.37 \\
\hline & 4.0 & 0 & 0 & 9 & 0.9654 & 9.0 & 0 & 1 & 4 & 0.9728 & 5.33 \\
\hline \multirow[t]{6}{*}{0.05} & 1.5 & 6 & 10 & 47 & 0.9576 & 68.47 & 13 & 20 & 40 & 0.9560 & 87.61 \\
\hline & 2.0 & 1 & 3 & 19 & 0.9599 & 24.74 & 5 & 8 & 19 & 0.9587 & 26.83 \\
\hline & 2.5 & 0 & 2 & 12 & 0.9921 & 18.72 & 2 & 4 & 11 & 0.9572 & 14.50 \\
\hline & 3.0 & 0 & 1 & 11 & 0.9857 & 13.01 & 1 & 3 & 9 & 0.9741 & 11.75 \\
\hline & 3.5 & 0 & 1 & 11 & 0.9965 & 13.01 & 0 & 2 & 6 & 0.9808 & 8.93 \\
\hline & 4.0 & 0 & 0 & 11 & 0.9579 & 11.0 & 0 & 1 & 5 & 0.9546 & 5.92 \\
\hline \multirow[t]{6}{*}{0.01} & 1.5 & 7 & 12 & 57 & 0.9638 & 81.12 & 8 & 19 & 34 & 0.9582 & 172.38 \\
\hline & 2.0 & 1 & 4 & 25 & 0.9677 & 31.51 & 5 & 10 & 24 & 0.9518 & 32.75 \\
\hline & 2.5 & 0 & 2 & 17 & 0.9750 & 20.14 & 2 & 5 & 14 & 0.9555 & 17.62 \\
\hline & 3.0 & 0 & 1 & 17 & 0.9643 & 17.75 & 0 & 3 & 8 & 0.9683 & 12.48 \\
\hline & 3.5 & 0 & 1 & 17 & 0.9913 & 17.75 & 0 & 3 & 9 & 0.9879 & 12.03 \\
\hline & 4.0 & 0 & 1 & 17 & 0.9978 & 17.75 & 0 & 2 & 8 & 0.9822 & 9.30 \\
\hline
\end{tabular}

Table 2: Minimum average sample number (ASN) and acceptance numbers when $\gamma=2$

\begin{tabular}{|c|c|c|c|c|c|c|c|c|c|c|c|}
\hline \multirow{3}{*}{$\beta$} & & \multicolumn{1}{|c|}{$\mathrm{a}=0.5$} & \multicolumn{1}{|c|}{} & $\mathrm{a}=1.0$ & & \\
\cline { 3 - 11 } & $\mathrm{r}_{2}$ & $\mathrm{C}_{1}$ & $\mathrm{C}_{2}$ & $\mathrm{n}$ & $\mathrm{p}_{\alpha}$ & $\mathrm{ASN}$ & $\mathrm{C}_{1}$ & $\mathrm{C}_{2}$ & $\mathrm{n}$ & $\mathrm{p}_{\alpha}$ & $\mathrm{ASN}$ \\
\hline 0.25 & 1.5 & 0 & 2 & 13 & 0.9572 & 28.89 & 9 & 10 & 23 & 0.9520 & 26.63 \\
& 2.0 & 0 & 1 & 11 & 0.9885 & 15.89 & 2 & 3 & 8 & 0.9676 & 10.24 \\
& 2.5 & 0 & 0 & 8 & 0.9661 & 8.0 & 0 & 1 & 3 & 0.9701 & 4.80 \\
& 3.0 & 0 & 0 & 8 & 0.9896 & 8.0 & 0 & 1 & 3 & 0.9917 & 4.80 \\
& 3.5 & 0 & 0 & 8 & 0.9972 & 8.0 & 0 & 1 & 3 & 0.9971 & 4.80 \\
& 4.0 & 0 & 0 & 8 & 0.9991 & 8.0 & 0 & 0 & 3 & 0.9568 & 3.0 \\
\hline 0.10 & 1.5 & 0 & 3 & 21 & 0.9517 & 45.13 & 8 & 11 & 25 & 0.9517 & 35.29 \\
& 2.0 & 0 & 1 & 15 & 0.9779 & 18.96 & 1 & 3 & 8 & 0.9546 & 11.91 \\
& 2.5 & 0 & 1 & 15 & 0.9980 & 18.96 & 1 & 2 & 7 & 0.9779 & 8.37 \\
& 3.0 & 0 & 0 & 14 & 0.9819 & 14.0 & 0 & 1 & 4 & 0.9834 & 5.33 \\
& 3.5 & 0 & 0 & 14 & 0.9951 & 14.0 & 0 & 1 & 4 & 0.9953 & 5.33 \\
& 4.0 & 0 & 0 & 14 & 0.9984 & 14.0 & 0 & 1 & 4 & 0.9986 & 5.33 \\
\hline 0.05 & 1.5 & 1 & 4 & 34 & 0.9540 & 50.51 & 8 & 12 & 27 & 0.9552 & 40.0 \\
& 2.0 & 0 & 1 & 19 & 0.9639 & 21.88 & 2 & 4 & 11 & 0.9690 & 14.51 \\
& 2.5 & 0 & 1 & 19 & 0.9967 & 21.88 & 0 & 2 & 6 & 0.9791 & 8.93 \\
& 3.0 & 0 & 0 & 18 & 0.9768 & 18.0 & 0 & 1 & 5 & 0.9722 & 5.92 \\
& 3.5 & 0 & 0 & 18 & 0.9937 & 18.0 & 0 & 1 & 5 & 0.9921 & 5.92 \\
& 4.0 & 0 & 0 & 18 & 0.9980 & 18.0 & 0 & 1 & 5 & 0.9977 & 5.92 \\
\hline 0.01 & 1.5 & 1 & 5 & 43 & 0.9542 & 60.51 & 8 & 14 & 31 & 0.9583 & 48.10
\end{tabular}




\begin{tabular}{|c|c|c|c|c|c|c|c|c|c|c|c|}
2.0 & 0 & 2 & 28 & 0.9898 & 32.72 & 1 & 4 & 11 & 0.9502 & 15.04 \\
& 2.5 & 0 & 1 & 27 & 0.9932 & 28.31 & 0 & 3 & 9 & 0.9791 & 12.03 \\
3.0 & 0 & 0 & 27 & 0.9654 & 27.0 & 0 & 2 & 8 & 0.9916 & 9.31 \\
& 3.5 & 0 & 0 & 27 & 0.9905 & 27.0 & 0 & 1 & 7 & 0.9833 & 7.40 \\
4.0 & 0 & 0 & 27 & 0.9970 & 27.0 & 0 & 1 & 7 & 0.9952 & 7.40 \\
\hline
\end{tabular}

Table 3: Minimum average sample number (ASN) and acceptance numbers when $\gamma=3$

\begin{tabular}{|c|c|c|c|c|c|c|c|c|c|c|c|}
\hline \multirow{2}{*}{$\beta$} & \multirow{2}{*}{$\mathrm{r}_{2}$} & \multicolumn{5}{|c|}{$a=0.5$} & \multicolumn{5}{|c|}{$a=1.0$} \\
\hline & & $\overline{C_{1}}$ & $\mathrm{C}_{2}$ & $\mathrm{n}$ & $\mathrm{P}_{\alpha}$ & ASN & $\mathrm{C}_{1}$ & $\overline{C_{2}}$ & $\bar{n}$ & $P_{\alpha}$ & ASN \\
\hline \multirow[t]{6}{*}{0.25} & 1.5 & 2 & 2 & 32 & 0.9528 & 32.0 & 3 & 5 & 11 & 0.9516 & 18.08 \\
\hline & 2.0 & 0 & 1 & 14 & 0.9974 & 20.54 & 1 & 2 & 6 & 0.9699 & 7.87 \\
\hline & 2.5 & 0 & 0 & 11 & 0.9882 & 11.0 & 0 & 1 & 3 & 0.9895 & 4.82 \\
\hline & 3.0 & 0 & 0 & 11 & 0.9976 & 11.0 & 0 & 1 & 3 & 0.9979 & 4.82 \\
\hline & 3.5 & 0 & 0 & 11 & 0.9995 & 11.0 & 0 & 0 & 3 & 0.9658 & 3.0 \\
\hline & 4.0 & 0 & 0 & 11 & 0.9999 & 11.0 & 0 & 0 & 3 & 0.9844 & 3.0 \\
\hline \multirow[t]{6}{*}{0.10} & 1.5 & 0 & 2 & 23 & 0.9652 & 39.24 & 3 & 6 & 13 & 0.9575 & 24.15 \\
\hline & 2.0 & 0 & 1 & 20 & 0.9946 & 25.36 & 1 & 2 & 7 & 0.9503 & 8.40 \\
\hline & 2.5 & 0 & 0 & 18 & 0.9809 & 18.0 & 0 & 1 & 4 & 0.9788 & 5.35 \\
\hline & 3.0 & 0 & 0 & 18 & 0.9960 & 18.0 & 0 & 1 & 4 & 0.9958 & 5.35 \\
\hline & 3.5 & 0 & 0 & 18 & 0.9992 & 18.0 & 0 & 0 & 4 & 0.9547 & 4.0 \\
\hline & 4.0 & 0 & 0 & 18 & 0.9998 & 18.0 & 0 & 0 & 4 & 0.9793 & 4.0 \\
\hline \multirow[t]{6}{*}{0.05} & 1.5 & 1 & 3 & 41 & 0.9729 & $\begin{array}{l}52.79 \\
\end{array}$ & 5 & 8 & 19 & 0.9557 & 27.19 \\
\hline & 2.0 & 0 & 1 & 25 & 0.9914 & 29.04 & 1 & 3 & 9 & 0.9779 & 11.84 \\
\hline & 2.5 & 0 & 0 & 24 & 0.9746 & 24.0 & 0 & 1 & 5 & 0.9645 & 5.94 \\
\hline & 3.0 & 0 & 0 & 24 & 0.9947 & 24.0 & 0 & 1 & 5 & 0.9930 & 5.94 \\
\hline & 3.5 & 0 & 0 & 24 & 0.9990 & 24.0 & 0 & 1 & 5 & 0.9986 & 5.94 \\
\hline & 4.0 & 0 & 0 & 24 & 0.9997 & 24.0 & 0 & 0 & 5 & 0.9742 & 5.0 \\
\hline \multirow[t]{6}{*}{0.01} & 1.5 & 0 & 3 & 39 & 0.9558 & 54.80 & 6 & 11 & 27 & 0.9517 & 35.02 \\
\hline & 2.0 & 0 & 1 & 37 & 0.9808 & 38.71 & 0 & 3 & 9 & 0.9521 & 12.14 \\
\hline & 2.5 & 0 & 0 & 36 & 0.9621 & 36.0 & 0 & 2 & 8 & 0.9878 & 9.35 \\
\hline & 3.0 & 0 & 0 & 36 & 0.9921 & 36.0 & 0 & 1 & 7 & 0.9853 & 7.42 \\
\hline & 3.5 & 0 & 0 & 36 & 0.9985 & 36.0 & 0 & 1 & 7 & 0.9971 & 7.42 \\
\hline & 4.0 & 0 & 0 & 36 & 0.9996 & 36.0 & 0 & 0 & 7 & 0.9641 & 7.0 \\
\hline
\end{tabular}

Table 4: Comparison between RASP and single acceptance sampling plan

\begin{tabular}{|c|c|c|c|c|c|c|c|c|c|c|c|c|c|}
\hline \multirow{3}{*}{$\beta$} & \multirow{3}{*}{$\mathrm{r}_{2}$} & \multicolumn{4}{|l|}{$\gamma=1$} & \multicolumn{4}{|l|}{$\gamma=2$} & \multicolumn{4}{|l|}{$\gamma=3$} \\
\hline & & \multicolumn{2}{|l|}{$\mathrm{a}=0.5$} & \multicolumn{2}{|l|}{$a=1.0$} & \multicolumn{2}{|l|}{$a=0.5$} & \multicolumn{2}{|l|}{$\mathrm{a}=1.0$} & \multicolumn{2}{|l|}{$a=0.5$} & \multicolumn{2}{|l|}{$a=1.0$} \\
\hline & & ASN & $\mathrm{n}(\mathrm{c})$ & ASN & $\mathrm{n}(\mathrm{c})$ & ASN & $\mathrm{n}(\mathrm{c})$ & ASN & $\mathrm{n}(\mathrm{c})$ & ASN & $\mathrm{n}(\mathrm{c})$ & ASN & $\mathrm{n}(\mathrm{c})$ \\
\hline \multirow{6}{*}{0.25} & 1.5 & 44.41 & $51(10)$ & 53.41 & $65(29)$ & 28.89 & $38(4)$ & 26.63 & $31(13)$ & 20.54 & $32(2)$ & 18.08 & $23(9)$ \\
\hline & 2.0 & 15.63 & 20(3) & 17.93 & 29(9) & 15.89 & $16(1)$ & 10.24 & $12(4)$ & 11.0 & $22(1)$ & 7.87 & $7(2)$ \\
\hline & 2.5 & 10.0 & $10(1)$ & 10.24 & 12(4) & 8.0 & $8(0)$ & 4.80 & $7(2)$ & 11.0 & $22(1)$ & 4.82 & $5(1)$ \\
\hline & 3.0 & 10.0 & $10(1)$ & 7.0 & $7(2)$ & 8.0 & $8(0)$ & 4.80 & $5(1)$ & 11.0 & $22(1)$ & 4.82 & $5(1)$ \\
\hline & 3.5 & 5.0 & $5(0)$ & 4.8 & $7(2)$ & 8.0 & $8(0)$ & 4.80 & $5(1)$ & 11.0 & $22(1)$ & 3.0 & $5(1)$ \\
\hline & 4.0 & 5.0 & $5(0)$ & 4.8 & $5(1)$ & 8.0 & $8(0)$ & 3.0 & $3(0)$ & 39.24 & $22(1)$ & 3.0 & $5(1)$ \\
\hline \multirow[t]{6}{*}{0.10} & 1.5 & 59.33 & $82(15)$ & 70.38 & $98(42)$ & 45.13 & $62(6)$ & 35.29 & $48(19)$ & 25.36 & $54(3)$ & 24.15 & $35(13)$ \\
\hline & 2.0 & 23.78 & $30(4)$ & 22.45 & $33(12)$ & 18.96 & $23(1)$ & 11.91 & $17(5)$ & 18.0 & $31(1)$ & 8.40 & $12(3)$ \\
\hline & 2.5 & 11.61 & $20(2)$ & 14.50 & 19(6) & 18.96 & $23(1)$ & 8.37 & $9(2)$ & 18.0 & $31(1)$ & 5.35 & $9(2)$ \\
\hline & 3.0 & 11.61 & $15(1)$ & 9.41 & 14(4) & 14.0 & $13(0)$ & 5.33 & $7(1)$ & 18.0 & $31(1)$ & 5.35 & 7(1) \\
\hline & 3.5 & 11.61 & $15(1)$ & 8.37 & $9(2)$ & 14.0 & $13(0)$ & 5.33 & $7(1)$ & 18.0 & $31(1)$ & 4.0 & 7(1) \\
\hline & 4.0 & 9.0 & $9(0)$ & 5.33 & $9(2)$ & 14.0 & $13(0)$ & 5.33 & $7(1)$ & 52.79 & $31(1)$ & 4.0 & $7(1)$ \\
\hline 0.05 & 1.5 & 68.47 & 107(19) & 87.61 & $126(53)$ & 50.51 & $77(7)$ & 40.0 & $60(23)$ & 29.04 & $74(4)$ & 27.19 & $42(15)$ \\
\hline
\end{tabular}




\begin{tabular}{|c|c|c|c|c|c|c|c|c|c|c|c|c|c|} 
& 2.0 & 24.74 & $40(5)$ & 26.83 & $42(15)$ & 21.88 & $37(2)$ & 14.51 & $21(6)$ & 24.0 & $38(1)$ & 11.84 & $16(4)$ \\
& 2.5 & 18.72 & $23(2)$ & 14.50 & $23(7)$ & 21.88 & $27(1)$ & 8.93 & $13(3)$ & 24.0 & $38(1)$ & 5.94 & $11(2)$ \\
& 3.0 & 13.01 & $18(1)$ & 11.75 & $16(4)$ & 18.0 & $17(0)$ & 5.92 & $11(2)$ & 24.0 & $38(1)$ & 5.94 & $8(1)$ \\
& 3.5 & 13.01 & $18(1)$ & 8.93 & $13(3)$ & 18.0 & $17(0)$ & 5.92 & $8(1)$ & 24.0 & $38(1)$ & 5.94 & $8(1)$ \\
& 4.0 & 11.0 & $11(0)$ & 5.92 & $11(2)$ & 18.0 & $17(0)$ & 5.92 & $8(1)$ & 54.80 & $38(1)$ & 5.0 & $8(1)$ \\
\hline 0.01 & 1.5 & 81.12 & $115(26)$ & 172.38 & $178(73)$ & 60.51 & $110(9)$ & 48.10 & $87(32)$ & 38.71 & $117(6)$ & 35.02 & $62(21)$ \\
& 2.0 & 31.51 & $60(7)$ & 32.75 & $59(20)$ & 32.72 & $48(2)$ & 15.04 & $30(8)$ & 36.0 & $53(1)$ & 12.14 & $22(5)$ \\
& 2.5 & 20.14 & $37(3)$ & 17.62 & $35(10)$ & 28.31 & $38(1)$ & 12.03 & $19(4)$ & 36.0 & $53(1)$ & 9.35 & $14(2)$ \\
& 3.0 & 17.75 & $31(2)$ & 12.48 & $22(5)$ & 27.0 & $26(0)$ & 9.31 & $14(2)$ & 36.0 & $53(1)$ & 7.42 & $11(1)$ \\
& 3.5 & 17.75 & $24(1)$ & 12.03 & $19(4)$ & 27.0 & $26(0)$ & 7.40 & $11(1)$ & 36.0 & $53(1)$ & 7.42 & $11(1)$ \\
& 4.0 & 17.75 & $24(1)$ & 9.30 & $17(3)$ & 27.0 & $26(0)$ & 7.40 & $11(1)$ & 20.54 & $53(1)$ & 7.0 & $11(1)$ \\
\hline
\end{tabular}

Table 5: Acceptance probabilities corresponding to true shape parameter $\gamma=3$ and $a=0.5$

\begin{tabular}{|c|c|c|c|c|c|c|c|c|c|c|c|}
\hline \multirow{2}{*}{$\beta$} & \multirow{2}{*}{$\mathrm{r}_{2}$} & \multicolumn{2}{|l|}{$\begin{array}{c}\gamma_{0}= \\
4.3 \\
\end{array}$} & \multicolumn{2}{|l|}{$\gamma_{0}=4.8$} & \multicolumn{2}{|l|}{$\begin{array}{c}\gamma_{\mathrm{o}}= \\
5.3\end{array}$} & \multicolumn{2}{|l|}{$\gamma_{0}=5.8$} & \multicolumn{2}{|l|}{$\gamma_{0}=6.3$} \\
\hline & & $\mathrm{p}_{\alpha}$ & $\mathrm{p}_{\beta}$ & $\mathrm{p}_{a}$ & $\mathrm{p}_{\beta}$ & $\mathrm{p}_{\alpha}$ & $\mathrm{p}_{\beta}$ & $\mathrm{p}_{\alpha}$ & $\mathrm{p}_{\beta}$ & $\mathrm{p}_{\alpha}$ & $\mathrm{p}_{\beta}$ \\
\hline \multirow[t]{4}{*}{0.25} & 1.5 & 0.9899 & 0.4277 & 0.9941 & 0.4907 & 0.9957 & 0.5405 & 0.9977 & 0.5982 & 0.9984 & 0.6418 \\
\hline & 2.0 & 0.9995 & 0.4114 & 0.9997 & 0.4706 & 0.9997 & 0.5182 & 0.9999 & 0.5740 & 0.9999 & 0.6169 \\
\hline & 2.5 & 0.9965 & 0.3415 & 0.9976 & 0.3818 & 0.9942 & 0.4097 & 0.9989 & 0.4432 & 0.9991 & 0.4696 \\
\hline & 3.0 & 0.9994 & 0.3415 & 0.9996 & 0.3818 & 0.9942 & 0.4097 & 0.9998 & 0.4432 & 0.9999 & 0.4696 \\
\hline \multirow[t]{4}{*}{0.10} & 1.5 & 0.9945 & 0.2361 & 0.9970 & 0.3062 & 0.9979 & 0.3690 & 0.9989 & 0.4496 & 0.9993 & 0.5152 \\
\hline & 2.0 & 0.9991 & 0.2071 & 0.9995 & 0.2546 & 0.9995 & 0.2964 & 0.9998 & 0.3502 & 0.9998 & 0.3953 \\
\hline & 2.5 & 0.9944 & 0.1770 & 0.9962 & 0.2069 & 0.9906 & 0.2322 & 0.9982 & 0.2640 & 0.9986 & 0.2903 \\
\hline & 3.0 & 0.9991 & 0.1777 & 0.9994 & 0.2069 & 0.9906 & 0.2322 & 0.9998 & 0.2640 & 0.9998 & 0.2903 \\
\hline
\end{tabular}

Table 6: Acceptance probabilities corresponding to true shape parameter $\gamma=3$ and a=1.0

\begin{tabular}{|c|c|c|c|c|c|c|c|c|c|c|c|}
\hline \multirow{2}{*}{$\beta$} & \multirow{2}{*}{$\mathrm{r}_{2}$} & \multicolumn{2}{|l|}{$\gamma_{0}=4.3$} & \multicolumn{2}{|l|}{$\gamma_{0}=4.8$} & \multicolumn{2}{|l|}{$\gamma_{0}=5.3$} & \multicolumn{2}{|l|}{$\begin{array}{c}\gamma_{\mathrm{o}}= \\
5.8\end{array}$} & \multicolumn{2}{|l|}{$\begin{array}{c}\gamma_{0}= \\
6.3\end{array}$} \\
\hline & & $\mathrm{p}_{\alpha}$ & $\mathrm{p}_{\beta}$ & $\mathrm{p}_{\alpha}$ & $\mathrm{p}_{\beta}$ & $\mathrm{p}_{\alpha}$ & $\mathrm{p}_{\beta}$ & $\mathrm{p}_{\alpha}$ & $\mathrm{p}_{\beta}$ & $\mathrm{p}_{\alpha}$ & $\mathrm{p}_{\beta}$ \\
\hline \multirow[t]{4}{*}{0.25} & 1.5 & 0.9749 & 0.1852 & 0.9795 & 0.1847 & 0.9827 & 0.1816 & 0.9861 & 0.1847 & 0.9985 & 0.1849 \\
\hline & 2.0 & 0.9796 & 0.2268 & 0.9841 & 0.2265 & 0.9869 & 0.2245 & 0.9898 & 0.2265 & 0.9916 & 0.2267 \\
\hline & 2.5 & 0.9957 & 0.2002 & 0.9968 & 0.2000 & 0.9974 & 0.1982 & 0.9981 & 0.2000 & 0.9984 & 0.2001 \\
\hline & 3.0 & 0.9993 & 0.2002 & 0.9995 & 0.2000 & 0.9996 & 0.1982 & 0.9997 & 0.2000 & 0.9998 & 0.2001 \\
\hline \multirow[t]{4}{*}{0.10} & 1.5 & 0.9803 & 0.0462 & 0.9849 & 0.0844 & 0.9877 & 0.0825 & 0.9906 & 0.0849 & 0.9924 & 0.0846 \\
\hline & 2.0 & 0.9771 & 0.0626 & 0.9824 & 0.0774 & 0.9857 & 0.0737 & 0.9889 & 0.0747 & 0.9910 & 0.0748 \\
\hline & 2.5 & 0.9913 & 0.0834 & 0.9936 & 0.0833 & 0.9948 & 0.0824 & 0.9961 & 0.0833 & 0.9969 & 0.0834 \\
\hline & 3.0 & 0.9987 & 0.0834 & 0.9991 & 0.0833 & 0.9993 & 0.0824 & 0.9995 & 0.0833 & 0.9969 & 0.0834 \\
\hline
\end{tabular}

